University of Nebraska - Lincoln

DigitalCommons@University of Nebraska - Lincoln

October 1999

\title{
Facilitating and Disinhibiting Prosocial Behaviors: The Nonlinear Interaction of Trait Perspective Taking and Trait Personal Distress on Volunteering
}

\author{
Gustavo Carlo \\ University of Nebraska-Lincoln, carlog@missouri.edu \\ James B. Allen \\ State University of New York-Geneseo, allen@geneseo.edu \\ Dion C. Buhman \\ University of Nebraska-Lincoln
}

Follow this and additional works at: https://digitalcommons.unl.edu/psychfacpub

Part of the Psychiatry and Psychology Commons

Carlo, Gustavo; Allen, James B.; and Buhman, Dion C., "Facilitating and Disinhibiting Prosocial Behaviors: The Nonlinear Interaction of Trait Perspective Taking and Trait Personal Distress on Volunteering" (1999). Faculty Publications, Department of Psychology. 88.

https://digitalcommons.unl.edu/psychfacpub/88

This Article is brought to you for free and open access by the Psychology, Department of at DigitalCommons@University of Nebraska - Lincoln. It has been accepted for inclusion in Faculty Publications, Department of Psychology by an authorized administrator of DigitalCommons@University of Nebraska - Lincoln. 


\title{
Facilitating and Disinhibiting Prosocial Behaviors: The Nonlinear Interaction of Trait Perspective Taking and Trait Personal Distress on Volunteering
}

\author{
Gustavo Carlo \\ Department of Psychology \\ University of Nebraska-Lincoln \\ James B. Allen \\ Department of Psychology \\ State University of New York-Geneseo \\ Dion C. Buhman \\ Department of Psychology \\ University of Nebraska-Lincoln
}

\begin{abstract}
Prior theorists and researchers have suggested that multiplicative models of prosocial behavior may account for weak and inconsistent relations between traits and prosocial behaviors. This study examined the multiplicative relations of trait personal distress, trait sympathy, and trait perspective taking on prosocial behaviors. Nonlinear, 2-way interactions were hypothesized, such that as trait personal distress decreased from moderate to low levels, and trait perspective taking or trait sympathy increased, volunteering would increase. One hundred and eighty-two undergraduate students completed a battery of trait measures that included trait perspective taking, trait sympathy, and trait personal distress. Approximately 6 weeks later, the students were given an opportunity to volunteer for a charity organization. Results indicated that there was a nonlinear multiplicative effect of trait perspective taking and trait personal distress on volunteering. Discussion focused on the implications of nonlinear, multiplicative trait models of prosocial behaviors.
\end{abstract}

Interest in and discussion of the relations among traits, motives, and social behaviors by social and personality psychologists (e.g., Bem \& Funder, 1978; Funder, 1991; Funder \& Colvin, 1991; Kenrick \& Funder, 1988; Kurtines, 1986; Snyder \& Ickes, 1985; Zuckerman, Bernieri, Koestner, \& Rosenthal, 1989) continues to evolve. Among a subset of social and personality researchers (see Batson, 1991; Eisenberg, 1986; Hoffman, 1991; Staub, 1978), there has been a continued interest in the role of motivation in predicting

Requests for reprints should be sent to either Gustavo Carlo, Department of Psychology, University of Nebraska-Lincoln, 320 Burnett Hall, Lincoln, NE 68588-0308, E-mail: gcarlo@unlinfo.unl.edu; or James B. Allen, Department of Psychology, State University of New York-Geneseo, Geneseo, NY 14454. prosocial behaviors (i.e., behaviors primarily intended to benefit another). One common belief among these researchers is that stronger and more consistent relations between traits and prosocial behaviors may be obtained by identifying important motivational constructs associated with these prosocial tendencies.

One reason for this attention to motivational constructs is that trait sociocognitive measures have often been shown to be only weakly related to prosocial behavior (e.g., Underwood \& Moore, 1982). A number of studies investigating the relation between various traits and prosocial behaviors have focused on trait sympathy (i.e., tendency to feel sorrow or concern for a needy other) and trait perspective taking (i.e., tendency to understand another's thoughts, feelings, or situation; see Batson, 1991; Davis, 1983; Eisenberg, 1986). Most 
authors assume that both trait perspective taking and trait sympathy often lead to prosocial behaviors because understanding of, and emotional responsiveness to, another's needs is purported to facilitate actions to relieve the other's distress. However, there is empirical evidence that these trait processes are weakly or often not consistently related to prosocial behaviors (see Eisenberg \& Miller, 1987; Underwood \& Moore, 1982), and others (e.g., Eisenberg, Shea, Carlo, \& Knight, 1991) have argued that there are situations in which these variables would not be expected to be related.

There are at least two reasons why researchers have found weak or inconsistent relations between trait sympathy and perspective taking and prosocial behavior. First, relatively strong and consistent correlations (Knight, Johnson, Carlo, \& Eisenberg, 1994; Staub, 1978) have been obtained by examining multiplicative, rather than additive, models of prosocial behaviors. Second, several theorists (Eisenberg, 1986; Hoffman, 1991; Staub, 1978) have argued that prosocial behaviors may require a motivational component that facilitates prosocial action. That is, although feeling sympathetic or understanding another's needy situation (i.e., perspective taking) may predispose an individual to help, helping behaviors may require a specific level of trait arousal to facilitate action tendencies. These suggestions imply that trait-by-trait interactions or multitrait models (cf. Funder, 1991) of prosocial behavior may be useful. The interactive nature of trait sympathy, personal distress, and perspective taking in predicting prosocial behavior has not been directly examined in prior work.

Trait personal distress is a candidate for moderating the relations between both trait sympathy and trait perspective taking and prosocial behavior. Trait personal distress (sometimes referred to as empathic distress) has been described by several authors (Batson, 1991; Davis, 1983; Davis, Luce, \& Kraus, 1994; Eisenberg, 1986; Hoffman, 1982) as a disposition to be self-focused and to feel uncomfortable when someone else needs help. Similar to trait sympathy and trait perspective taking, trait personal distress reactions often stem from a tendency to observe the experiences of needy others. However, unlike both trait perspective taking and trait sympathy, trait personal distress reflects minimally sophisticated cognitive processes (Eisenberg \& Fabes, 1992), and is an early emerging developmental process (Hoffman, 1991). Furthermore, a number of investigators have argued that trait personal distress may reflect high levels of general trait emotionality (Archer, Diaz-Loving, Gollwitzer, Davis, \& Foushee, 1981; Davis, 1983; Davis et al., 1994; Hoffman, 1982), which may be personally aversive. Others (Coke, Batson, \& McDavis, 1978; Krebs, 1975) have pointed out that high levels of trait personal distress are associated with high levels of trait arousal. In a recent discussion of the interrelations among trait personal distress, trait perspective taking, and trait sympathy, Eisenberg et al. (1991) suggested that high levels of trait personal distress is arousing and may interfere with well-regulated processes such as trait sympa- thy and trait perspective taking. Furthermore, Easterbrook (1959) and others (e.g., Mandler, 1975) argued that arousal narrows the focus of attention, thus making it more difficult to attend to needy others. Furthermore, according to the Yerkes-Dodson Law (Hebb, 1955), arousal affects performance in a nonlinear manner with optimal performance at moderate levels of arousal. As a result, cognitive processes may be overwhelmed by arousal processes. Following these arguments, individuals with high levels of trait personal distress (i.e., arousal) may be predisposed to lower levels of trait perspective taking and trait sympathy.

Thus, one might expect relatively weak relations between trait personal distress and both trait sympathy and trait perspective taking (and other trait cognitions) and relatively strong relations to markers of trait emotionality. Prior research supports these expectations. For instance, Archer et al. (1981) found separate loadings for two personal distress factors (sad and anger types) and a sympathy factor. Similarly, Batson (1991) and others (Carlo, Eisenberg, Troyer, Switzer, \& Speer, 1991; Eisenberg, Miller, Schaller, Fabes, Fultz, Shell, \& Shea, 1989) found that trait personal distress loaded on a different factor than trait perspective taking and trait sympathy. In addition, Davis (1983) showed that trait personal distress was strongly positively related to several markers of trait emotionality, including trait anxiety and unrelated or weakly related to trait perspective taking and vocabulary test scores. Finally, other researchers (Carlo, Eisenberg, \& Knight, 1992) found that trait personal distress was negatively related, and trait sympathy was positively related, to trait prosocial moral reasoning. As can be surmised, in general, trait personal distress tendencies are consistently positively associated with other markers of trait emotionality but not strongly or negatively related to markers of trait cognition including trait perspective taking.

In several prior studies (Carlo et al., 1991; Eisenberg, Miller, et al., 1989; see Batson, 1991), investigators have shown that trait personal distress often leads to egoistically motivated helping or to no helping. However, this research was predicated primarily on the nature of relatively high levels of trait personal distress and focused on the main effect of trait personal distress on helping. We know less about the relations between trait personal distress and prosocial behavior when specific levels (i.e., low vs. moderate vs. high) of the distress tendency interact with trait sympathy or perspective taking. That is, it may be that helping responses depend on the individual's trait level of personal distress and how it interacts with trait perspective taking and trait sympathy. A low-level personal distress tendency combined with high levels of either trait perspective taking or sympathy may be amenable to helping behaviors, because such tendencies would disinhibit or motivate individuals who are predisposed to help across different helping situations. However, as the level of trait personal distress increases from low to moderate or high, individuals may be disposed to avoid helping needy others because their other-oriented tendencies be- 
come overwhelmed by arousal. Note that, even when high levels of other-oriented traits are present, if the trait level of personal distress is high, there is less likelihood of helping. These arguments suggest that trait personal distress may interact with trait perspective taking and trait sympathy when predicting prosocial behavior.

Furthermore, there are reasons to suspect that these interactions may be nonlinear in nature. Recall from the earlier discussion that personal distress has arousal properties. Previous researchers have demonstrated that arousal narrows the focus of attention (Easterbrook, 1959; Mandler, 1975) and affects behavior in a nonlinear manner (Hebb, 1955). Extrapolating to the present issue, it is likely that trait personal distress may narrow the focus of attention and overwhelm sociocognitive tendencies such as trait perspective taking and trait sympathy. Thus, specific levels of trait personal distress and either trait perspective taking or trait sympathy may be multiplicatively related to prosocial behaviors in a nonlinear manner.

To our knowledge, researchers have not examined the linear or nonlinear interactive effects of trait personal distress and either trait sympathy or trait perspective taking on prosocial behaviors. Nonlinear relations between trait emotions and trait cognitions and prosocial behaviors were expected. High or moderate levels of trait personal distress would be expected to overwhelm trait sympathy and trait perspective taking. In contrast, at low levels of trait personal distress, high levels of trait perspective taking and sympathy would be expected to overwhelm trait personal distress. Thus, a nonlinear, two-way interaction effect was expected, such that as trait perspective taking increased to high levels and trait personal distress decreased from moderate or high levels to low levels, volunteering was expected to increase. Similarly, a nonlinear, two-way interaction effect was expected, such that as trait sympathy increased to high levels and trait personal distress decreased from moderate or high levels to low levels, volunteering was expected to increase. High or moderate levels of trait personal distress combined with low or moderate levels of trait perspective taking and trait sympathy were not expected to be significantly associated with volunteering. Based on the notion that individuals may have a tendency to report themselves in a positive light (Archer, 1984; Cialdini et al., 1987), trait social desirability was assessed as a covariate.

\section{METHOD}

\section{Participants}

Participants were 182 introductory psychology students (121 women, $61 \mathrm{men}$ ) from a relatively small state university in New York. All participants served in two experimental sessions and received credit toward their course grade.

\section{Instruments and Procedure}

There were two experimental sessions spaced approximately 6 weeks apart. In the first session, participants (in groups of about 15-20) were administered a packet of randomly ordered trait questionnaires that included:

Trait sympathy and related responding. The sympathy (i.e., empathic concern), perspective taking, and personal distress subscales of a multidimensional measure of trait empathy (Davis, 1983) were used. Each subscale consisted of 7 items measured on a scale, from 1 (Not descriptive of me) to 5 (Descriptive of me). Sample items included: "I often have tender, concerning feelings for people less fortunate than me," and "I am often quite touched by things I see happen" (sympathy; Cronbach's alpha in the present study =.73); "I try to look at everybody's side of a disagreement before I make a decision" and "I believe there are two sides to every question and I try to look at them both" (perspective taking; alpha in the present study = .79); and "In emergency situations, I feel anxious and ill-at ease" and "When I see someone get hurt, I tend to remain calm" (personal distress; alpha in the present study $=.80$ ).

The three subscales of the empathy measure have been found to correlate significantly with facial expression indices of empathy, other paper-and-pencil measures of empathy and emotionality, psychophysiological indices of emotional responding, and social behaviors (e.g., Carlo et al., 1991; Davis, 1983; Davis, Hull, Young, \& Warren, 1987; Eisenberg, Fabes, et al., 1989; Eisenberg, Miller, et al., 1989). Thus, there is evidence of adequate psychometric properties of the measure.

Trait social desirability. To assess participants' tendencies to present themselves in a positive manner, participants completed 33 true-false items from a social desirability scale (Crowne \& Marlowe, 1964). Sample items included: "Before voting I thoroughly investigate the qualifications of all the candidates," and "I have never intensely disliked someone" (alpha in the present study $=.78$ ).

Intent to volunteer. As in much of the prior research on prosocial behaviors (see Batson, 1991; Eagly \& Crowley, 1986), an opportunity was presented to participants to report their intention to volunteer. Approximately 6 weeks after participants completed the previously described measures, a representative from a local volunteer organization (a real volunteer center at the university) presented participants with an opportunity to volunteer time in one or more of the following areas: aging, handicapped services, tutoring (helping poor and disadvantaged children with homework), crisis management (including helping battered women), and youth services (including helping abused children). All participants received a university letter-headed volunteer form in which they could indicate if they were or were not interested in volunteering. If they were interested in volunteering, there was a section on 
the form asking how many sessions (approximately $1 \mathrm{hr}$ each session) they would be willing to volunteer (scores ranged from 1 to 2 sessions up to 19 or more sessions). Participants who indicated an interest in volunteering were subsequently contacted by the organization. There was no obvious link between the volunteer opportunity and the previous questionnaire session.

\section{RESULTS}

\section{Preliminary Analyses}

Means, standard deviations, and ranges of scores for trait perspective taking, trait sympathy, trait personal distress, trait social desirability, and intent to volunteer for the total sample and for each gender group are presented in Table 1. Preliminary correlational analyses (all tests were twotailed) were conducted to assess the interrelations among the variables of interest. Examination of the relations among trait personal distress, trait perspective taking, and trait sympathy revealed modest or nonsignificant correlations (see Table 2). These findings were consistent with prior findings (e.g., Carlo et al., 1991; Davis, 1983; Davis et al., 1994) that suggest the relative independence of these constructs. Consistent with prior findings (Carlo et al., 1991; Eisenberg, Miller, et al., 1989), both trait sympathy and trait perspective taking were related positively to volunteering. Trait social desirability was related positively to trait perspective taking and trait sympathy and negatively to trait personal distress.
A series of analyses of variance (ANOVAs) was conducted to examine gender differences in trait sympathy, trait perspective taking, trait personal distress, trait social desirability, and volunteering. Consistent with prior findings (see Eagly \& Crowley, 1986; Eisenberg, 1986), these analyses revealed that females scored higher than males (see Table 1 for means) on trait perspective taking, trait sympathy, trait social desirability, trait personal distress and volunteering, $F(1$, 173) $=5.94, p<.02, \eta^{2}=.03 ; F(1,173)=5.94, p<.02, \eta^{2}=$ $.03 ; F(1,167)=5.08, p<.03, \eta^{2}=.03 ; F(1,174)=10.61, p<$ $.002, \eta^{2}=.06$; and $F(1,174)=12.04, p<.001, \eta^{2}=.06$, respectively. Because gender and social desirability were associated with the variables of interest, both variables were included as covariates in the main analyses.

\section{Main Analyses}

A hierarchical multiple regression analysis was conducted to examine the linear and nonlinear interactive effect of trait personal distress on the relations between both trait perspective taking and trait sympathy on intent to volunteer. All variables were centered (by subtracting the means) prior to the analyses to reduce nonessential collinearity from computing the interaction vectors (see Aiken \& West, 1991). Because we expected nonlinear relations and following Pedhauzer's (1982) procedures, the quadratic main and interaction effects of trait personal distress, trait perspective taking, and trait sympathy were examined in these analyses. Furthermore, as mentioned previously, gender and social desirability were statistically controlled in this analysis (see Hull, Tedlie, \& Lehn, 1992).

TABLE 1

Means, Standard Deviations, and Ranges of Scores for Perspective Taking, Personal Distress, Social Desirability, Sympathy, and Volunteering, for the Total Sample and by Gender

\begin{tabular}{|c|c|c|c|c|c|c|c|}
\hline \multirow[b]{2}{*}{ Group } & \multicolumn{3}{|c|}{ Total Sample } & \multicolumn{2}{|c|}{ Men } & \multicolumn{2}{|c|}{ Women } \\
\hline & $M$ & $S D$ & Range & $M$ & $S D$ & $M$ & $S D$ \\
\hline Perspective taking & 25.00 & 4.49 & $13-35$ & 23.76 & 4.41 & 25.53 & 4.46 \\
\hline Personal distress & 18.79 & 4.97 & $8-33$ & 17.02 & 4.90 & 19.63 & 4.90 \\
\hline Social desirability & 14.19 & 5.30 & $1-31$ & 12.77 & 4.61 & 14.75 & 5.55 \\
\hline Sympathy & 28.13 & 3.88 & $18-35$ & 26.15 & 4.12 & 29.09 & 3.49 \\
\hline Volunteering & 2.17 & 2.82 & $0-10$ & 1.17 & 1.92 & 2.74 & 3.06 \\
\hline
\end{tabular}

Note. Ns for the total sample ranged from 175 to 182 .

TABLE 2

Correlations Among Perspective Taking, Sympathy, Personal Distress, Volunteering, and Social Desirability

\begin{tabular}{lcccc}
\hline Variable & Sympathy & Personal Distress & Volunteering & Social Desirability \\
\hline Perspective taking & $.39 * * *$ & -.03 & $.17^{*}$ & $.36^{* * *}$ \\
Sympathy & - & $.20^{* *}$ & $.24^{* *}$ & $.20^{* *}$ \\
Personal distress & & - & .04 & $-.20^{* *}$ \\
Volunteering & & - & .06 \\
Social desirability & & & - \\
\hline${ }^{*} p<.05 .^{* *} p<.01 .^{* * *} p<.001$. & &
\end{tabular}


TABLE 3

Multiple Regression Analysis for the Predictors on Volunteering

\begin{tabular}{|c|c|c|c|c|}
\hline Variable Entered & F Change for Step & $p$ & $R^{2}$ Change & Standardized B \\
\hline Step 1 & $F$ change $(5,159)=3.86$ & $<.003$ & 0.11 & \\
\hline Social desirability & & & & -.05 \\
\hline Gender & & & & $-.23 * *$ \\
\hline Sympathy & & & & .15 \\
\hline Personal distress & & & & -.06 \\
\hline Perspective taking & & & & .09 \\
\hline Step 2 & $F$ change $(14,145)=.67$ & $<.80$ & 0.05 & \\
\hline Social desirability & & & & -.07 \\
\hline Gender & & & & $-.24 *$ \\
\hline Sympathy & & & & .14 \\
\hline Personal distress & & & & -.04 \\
\hline Perspective taking & & & & .12 \\
\hline Sympathy $\times$ Social Desirability & & & & -.03 \\
\hline Personal Distress $\times$ Social Desirability & & & & .03 \\
\hline Gender $\times$ Personal Distress & & & & .02 \\
\hline Perspective Taking $\times$ Perspective Taking & & & & -.04 \\
\hline Perspective Taking $\times$ Personal Distress & & & & .12 \\
\hline Personal Distress $\times$ Personal Distress & & & & -.09 \\
\hline Gender $\times$ Sympathy & & & & -.07 \\
\hline Gender $\times$ Perspective Taking & & & & -.02 \\
\hline Social Desirability $\times$ Social Desirability & & & & -.04 \\
\hline Sympathy $\times$ Sympathy & & & & .02 \\
\hline Gender $\times$ Social Desirability & & & & -.06 \\
\hline Sympathy $\times$ Personal Distress & & & & -.12 \\
\hline Perspective Taking $\times$ Sympathy & & & & -.01 \\
\hline Perspective Taking $\times$ Social Desirability & & & & .09 \\
\hline Step 3 & $F$ change $(2,143)=4.40$ & $<.02$ & 0.05 & \\
\hline Social desirability & & & & -.11 \\
\hline Gender & & & & $-.24 * *$ \\
\hline Sympathy & & & & .20 \\
\hline Personal distress & & & & -.04 \\
\hline Perspective taking & & & & $.31 *$ \\
\hline Sympathy $\times$ Social Desirability & & & & -.05 \\
\hline Personal Distress $\times$ Social Desirability & & & & .04 \\
\hline Gender $\times$ Personal Distress & & & & .05 \\
\hline Perspective Taking $\times$ Perspective Taking & & & & -.04 \\
\hline Perspective Taking $\times$ Personal Distress & & & & .09 \\
\hline Personal Distress $\times$ Personal Distress & & & & -.06 \\
\hline Gender $\times$ Sympathy & & & & -.06 \\
\hline Gender $\times$ Perspective Taking & & & & -.04 \\
\hline Social Desirability $\times$ Social Desirability & & & & -.01 \\
\hline Gender $\times$ Social Desirability & & & & -.04 \\
\hline Sympathy $\times$ Sympathy & & & & .06 \\
\hline Sympathy $\times$ Personal Distress & & & & -.13 \\
\hline Perspective Taking $\times$ Sympathy & & & & .04 \\
\hline Perspective Taking $\times$ Social Desirability & & & & .06 \\
\hline Personal Distress $\times$ Personal Distress $\times$ Sympathy & & & & -.11 \\
\hline Personal Distress $\times$ Personal Distress $\times$ Perspective Taking & & & & $-.27 *$ \\
\hline
\end{tabular}

Note. Females were coded as 0 , and males were coded as 1 .

${ }^{*} p<.05 .{ }^{* *} p<.01$.

Regression diagnostic procedures (see Tabachnick \& Fidell, 1989) were used to identify potential influential cases and to test for multicollinearity; no influential cases were identified and tolerance levels were acceptable.

In the main analysis (see Table 3 ), trait personal distress, trait perspective taking, trait sympathy, trait social desirabil- ity, and gender were entered on the first step. All possible linear two-way interactions and the quadratic main effects were entered on the second step. The predicted Personal Distress $\times$ Personal Distress $\times$ Perspective Taking interaction (the Perspective Taking $\times$ Quadratic Personal Distress interaction) and the predicted Personal Distress $\times$ Personal Distress $\times$ 
Sympathy interaction (the Sympathy $\times$ Quadratic Personal Distress interaction) were entered on the third step. On the fourth step, the other linear three-way interactions, the other quadratic interactions and the cubic main effects were entered to test the robustness of the predicted three-way interactions entered on the third step.

As can be seen in Table 3, in the first two steps of the model, the only significant predictor of volunteering was gender. Females volunteered more than males. There were no significant main effects of trait social desirability, trait personal distress, or trait perspective taking. There was also no significant linear interaction of Personal Distress $\times$ Perspective Taking, or significant quadratic main effects of trait personal distress or trait perspective taking. In the third step, the addition of the Perspective Taking $\times$ Quadratic Personal Distress interaction contributed a significant change in $R^{2}$ (multiple $R^{2}=.21$ ) over and above the covariates, the main effects, the linear interaction effects, and the quadratic main effects (see Table 3). Moreover, women and is lividuals with high levels of trait perspective taking were more iin : : to volunteer. The addition of the other three-way interactions, other quadratic interactions and the cubic main effects in Step 4 did not add significant explained variance in volunteering, $R^{2}$ change $=.11, F$ change $(28,115)=.66, n s$. However, the Quadratic Personal Distress $\times$ Perspective Taking interaction became nonsignificant on Step 4.

The simple regression slopes of significant interaction effects of continuous variables were tested using the procedure outlined by Aiken and West (1991). Regression lines describing the relation between trait personal distress and volunteering were plotted separately at three levels of trait perspective taking corresponding to the mean and points 1 standard deviation above and below the mean. The specific simple regression lines depicted in Figure 1 represent the nature of the interaction (a three-dimensional surface can only represent a complete view of the interaction). Tests of the simple regression slopes for the significant Perspective Taking $\times$ Quadratic Personal Distress interaction showed that as perspective taking increased, volunteering increased, but only at low levels of personal distress (see Figure 1), $t(143)=2.63, p<.01$ (two-tailed). No other simple regression slopes were significantly different from $0, t \mathrm{~s}(143)=1.63$ and $.92, n s$.

\section{DISCUSSION}

There was partial support for the main hypotheses. Consistent with expectations, there was a nonlinear interaction between trait personal distress and trait perspective taking to predict volunteering. Specifically, trait perspective taking was strongly and positively associated with volunteering when levels of trait personal distress were relatively low. However, for levels of trait personal distress that were moderate to high, the relations between trait perspective taking and volunteering were weak. In contrast, the quadratic trait personal distress by trait sympathy interaction was not a significant predictor of volunteering. Thus, trait perspective taking but not trait sympathy was multiplicatively related to quadratic trait personal distress in predicting volunteering.

These findings have several important implications. First, they demonstrate the efficacy of multiplicative, rather than main effect, models of personality traits to predict prosocial behaviors (see Kenrick \& Funder, 1988). As in

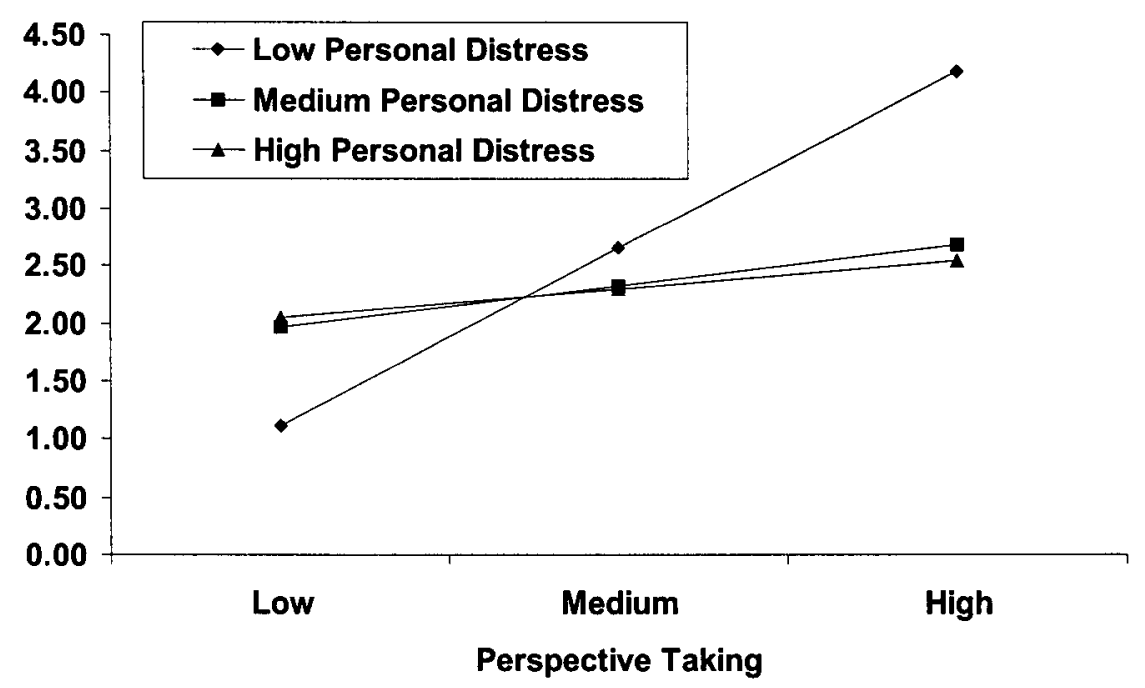

FIGURE 1 Volunteering as a function of perspective taking and personal distress (unstandardized regression coefficients for low, medium, and high personal distress were $.195, .006$, and .005 , respectively) 
prior research, there was no significant zero-order relation between trait personal distress and prosocial behavior and there were positive, modest zero-order relations between trait perspective taking and trait sympathy and prosocial behavior. However, it was the examination of the nonlinear, interactive effect of trait personal distress and trait perspective taking that revealed substantial amounts of explained variance in volunteering over and above the main effects. More specifically, the results revealed that high levels of volunteering were not simply a product of increasing trait perspective taking or of trait sympathy or of low trait personal distress (i.e., main effects), but rather, volunteering increased significantly only when high levels of trait perspective taking were present with low levels of trait personal distress. Furthermore, there was no significant increase in volunteering when there were high or moderate levels of trait personal distress and high levels of trait perspective taking. Thus, the examination of trait multiplicative models, rather than additive models, may better predict prosocial behaviors.

Second, to the extent that multiplicative models have been examined in earlier research, efforts have primarily focused on situational by trait cognitive or situational by trait affective interaction models of social behavior (Funder \& Colvin, 1991; Kenrick \& Funder, 1988; Knight et al., 1994; Kurtines, 1986). The examination of trait cognitive by trait affective interactions sheds further light on the joint effects of traits associated with prosocial behaviors and suggests the importance of examining the interactive role of personality and motivational constructs. The present findings support prior arguments that personality by personality (e.g., multitrait; Funder, 1991; Staub, 1978), interaction effects on social behaviors should be examined.

Third, although most conceptual models of prosocial behavior concern themselves with linear main and interaction effects, the present study suggests that examination of nonlinear relations may be fruitful for future researchers (cf. Pedhauzer, 1982). The nature of the present findings suggest that the relations between prosocial behaviors, trait perspective taking, and trait personal distress may have been underestimated in prior studies by examining linear, rather than nonlinear, relations. In the present study, examination of linear interactions would not have uncovered the nonlinear interactive effect that predicted volunteering. Future research is needed to examine the nonlinear, joint influence of other affective and cognitive traits that may be important predictors of prosocial behaviors. For example, previous researchers (e.g., Underwood \& Moore, 1982) have shown weak and inconsistent relations between trait moral reasoning and prosocial behaviors, and guilt has been associated with arousal (Hoffman, 1982). Because thinking and decisions about moral dilemmas often involve the consideration of consequences for one's self such as guilt, one would expect that intense feelings of guilt might overwhelm moral reasoning tendencies (particularly weak ten- dencies). Under these circumstances, the relation between trait moral reasoning and prosocial behaviors may be weak or nonsignificant. However, examination of nonlinear effects may reveal strong relations between moral reasoning and prosocial behaviors at low, but not high or moderate, levels of guilt.

And fourth, the present findings also support earlier notions (e.g., Davis, 1983; Davis et al., 1994) that empathy is a multidimensional construct. In the present study, trait personal distress, trait perspective taking, and trait sympathy were weakly or nonsignificantly interrelated. Furthermore, the nonlinear, two-way interaction of trait perspective taking and trait personal distress uniquely predicted volunteering over and above the contributions of each of the trait variables and their interactions. However, unexpectedly, the trait sympathy by quadratic personal distress interaction did not significantly predict volunteering. Perhaps the trait sympathy by trait personal distress interaction did not uniquely predict helping because of the disruptive nature of these trait emotions. Personal distress tendencies may be difficult to reconcile with sympathetic tendencies because individuals with personal distress tendencies are susceptible to relatively high levels of arousal. Following this argument, trait cognitions and trait emotions may be multiplicatively related to helping when both traits are oriented toward others, and consistent with helping others and when both traits are emotionally compatible (e.g., when trait emotions do not overwhelm trait cognitions). Nonetheless, the present findings suggest that trait personal distress, trait perspective taking, and trait sympathy are distinct constructs that make both independent and joint contributions to predict prosocial behaviors.

There are some limitations to the present findings. First, the nonlinear interactive effect of perspective taking and personal distress became nonsignificant when all possible gender and social desirability effects were entered. This suggests that the relations between prosocial traits and prosocial behaviors are influenced by gender and social desirability (see Carlo et al., 1991; Cialdini et al., 1987). Future replication studies with sample sizes adequate to examine the influence of gender, social desirability, and prosocial traits on prosocial behaviors are needed. Second, we expect that there would be different patterns of interactions between helping-related traits in predicting different types of prosocial behaviors (Knight et al., 1994). For example, one might expect a strong positive relation between trait perspective taking and comforting a needy other in an ambiguous situation (e.g., comforting an acquaintance who has lost a loved one) particularly at high levels of trait sympathy (a linear Sympathy $\times$ Perspective Taking interaction). In this situation, trait perspective taking may increase the likelihood of deciphering ambiguous emotional and situational cues, and trait sympathy may induce the individual to comfort the needy other. Third, the present study focused on trait rather than state variables. Future research examin- 
ing interaction models with state variables may be beneficial, to directly examine relatively more "on-line" interaction effects of helping; such research is currently under way.

On a final note, in light of the debate between theorists (e.g., Batson, 1991) who emphasize the selfless nature of helpful individuals and others (Cialdini et al., 1987) who emphasize the egoistic nature of helpful individuals, some egoistic (e.g., personal distress) and other-oriented (e.g., perspective taking) dispositions may function concurrently in predicting prosocial behaviors. For example, trait personal distress has often been described as an egoistically motivated response that mitigates prosocial behaviors (except in difficult-escape situations). However, the present findings yielded evidence that individuals may help others when they are prone to relatively low levels of trait personal distress and when combined with some other-oriented traits (i.e., perspective taking). Thus, individuals with low levels of trait personal distress were not overwhelmed with their egoism and when combined with high levels of trait perspective taking, these factors served to augment or at least disinhibit prosocial responding. As a result, helping may be a function of both egoistic and selfless traits. Individuals' dispositions for both egoistic and other-oriented traits may help explain why helping opportunities for many individuals often pose dilemmas that can be difficult to resolve and sheds light on this continuing debate.

\section{ACKNOWLEDGMENTS}

Portions of this article were presented at the June 1995 Meeting of the American Psychological Society, New York.

This project was supported through a Faculty Summer Fellowship to Gustavo Carlo from the Office of the Research Council and a Geneseo Presidential Summer Fellowship to James B. Allen.

We gratefully appreciate the assistance of Richard Dienstbier, Jacqueline A. McEwen, Mark Schaller, Diane E. True, and Karin L. Vermilye.

\section{REFERENCES}

Aiken, L. S., \& West, S. G. (1991). Multiple regression: Testing and interpreting interactions. Newbury Park, CA: Sage.

Archer, R. L. (1984). The farmer and the cowman should be friends: An attempt at reconciliation with Batson, Coke, and Pych. Journal of Personality and Social Psychology, 46, 709-711.

Archer, R. L., Diaz-Loving, R., Gollwitzer, P. M., Davis, M. H., \& Foushee, H. C. (1981). The role of dispositional empathy and social evaluation in the empathic mediation of helping. Journal of Personality and Social Psychology, 40, 786-796.

Batson, C. D. (1991). The altruism question. Hillsdale, NJ: Lawrence Erlbaum Associates, Inc.
Bem, D. J., \& Funder, D. C. (1978). Predicting more of the people more of the time: Assessing the personality of situations. Psychological Review, 85 , 485-501.

Carlo, G., Eisenberg, N., \& Knight, G. P. (1992). An objective measure of prosocial moral reasoning. Journal of Research on Adolescence, 2 , 331-349.

Carlo, G., Eisenberg, N., Troyer, D., Switzer, G., \& Speer, A. L. (1991). The altruistic personality: In what contexts is it apparent? Journal of Personality and Social Psychology, 61, 450-458.

Cialdini, R. B., Schaller, M., Houlihan, D., Arps, K., Fultz, J., \& Beaman, A. L. (1987). Empathy-based helping: Is it selflessly or selfishly motivated? Journal of Personality and Social Psychology, 52, 729-758.

Coke, J. S., Batson, C. D., \& McDavis, K. (1978). Empathic mediation of helping: A two-stage model. Journal of Personality and Social Psychology, 36, 752-766.

Crowne, D. P., \& Marlowe, D. (1964). The approval motive. New York: Wiley.

Davis, M.H. (1983). Measuring individual differences in empathy: Evidence for a multidimensional approach. Journal of Personality and Social Psychology, 44, 113-126.

Davis, M. H., Hull, J. G., Young, R. D., \& Warren, G. G. (1987). Emotional reactions to dramatic film stimuli: The influence of cognitive and emotional empathy. Journal of Personality and Social Psychology, 52, 126-133.

Davis, M. H., Luce, C., \& Kraus, S. J. (1994). The heritability of characteristics associated with dispositional empathy. Journal of Personality, 62. 369-391.

Eagly, A. H., \& Crowley, M. (1986). Gender and helping behavior: A meta-analytic review of the social psychological literature. Psychological Bulletin, 100, 283-308.

Easterbrook, J. A. (1959). The effect of emotion on cue utilization and the organization of behavior. Psychological Review, 66, 183-201.

Eisenberg, N. (1986). Altruistic emotion, cognition, and behavior. Hillsdale, NJ: Lawrence Erlbaum Associates, Inc.

Eisenberg, N., \& Fabes, R. A. (1992). Emotion, regulation, and the development of social competence. In M. S. Clark (Ed.), Review of personality and social psychology: Vol. 14. Emotion and social behavior (pp. 119-150). Newbury Park, CA: Sage.

Eisenberg, N., Fabes, R. A., Miller, P. A., Fultz, J., Shell, R., Mathy, R. M., \& Reno, R. (1989). The relation of sympathy and personal distress to prosocial behavior: A multimethod study. Journal of Personality and Social Psychology, 57, 55-66.

Eisenberg, N., \& Miller, P. A. (1987). The relation of empathy to prosocial and related behavior. Psychological Bulletin, 101, 91-119.

Eisenberg, N., Miller, P. A., Schaller, M., Fabes, R. A., Fultz, J., Shell, R., \& Shea, C. L. (1989). The role of sympathy and altruistic personality traits in helping: A reexamination. Journal of Personality, 57, 41-67.

Eisenberg, N., Shea, C. L., Carlo, G., \& Knight, G. P. (1991). Empathy-related responding and cognition: A "chicken and the egg" dilemma. In W. M. Kurtines \& J. L. Gewirtz (Eds.), Handbook of moral behavior and development: Vol. 2. Research (pp. 63-88). Hillsdale, NJ: Lawrence Erlbaum Associates, Inc.

Funder, D. C. (1991). Global traits: A neo-Allportian approach to personality. Psychological Science, 2, 31-39.

Funder, D. C., \& Colvin, R. (1991). Explorations in behavioral consistency: Properties of persons, situations, and behaviors. Journal of Personality and Social Psychology, 60, 773-794.

Hebb, D. O. (1955). Drives and the central nervous system. Psychological Review, 62, 243-253.

Hoffman, M. L. (1982). Development of prosocial motivation: Empathy and guilt. In N. Eisenberg (Ed.), The development of prosocial behavior (pp. 281-313). San Diego, CA: Academic.

Hoffman, M. L. (1991). Empathy, social cognition, and moral action. In W. M. Kurtines \& J. L. Gewirtz (Eds.), Handbook of moral behavior and development: Vol. 1. Theory (pp. 275-301). Hillsdale, NJ: Lawrence Erlbaum Associates, Inc 
Hull, J. G., Tedlie, J. G., \& Lehn, D. A. (1992). Moderator variables in personality research: The problem of controlling for plausible alternatives. Personality and Social Psychology Bulletin, 18, 115-117.

Kenrick, D. T., \& Funder, D. C. (1988). Profiting from controversy: Lessons from the person-situation debate. American Psychologist, 43, 23-34.

Knight, G. P., Johnson, L. G., Carlo, G., \& Eisenberg, N. (1994). A multiplicative model of the dispositional antecedents of a prosocial behavior: Predicting more of the people more of the time. Journal of Personality and Social Psychology, 66, 178-183.

Krebs, D. (1975). Empathy and altruism. Journal of Personality and Social Psychology, 32, 1134-1146.

Kurtines, W. M. (1986). Moral behavior as rule governed behavior: Person and situation effects on moral decision making. Journal of Personality and Social Psychology, 50, 784-791.

Mandler, G. (1975). Mind and emotion. New York: Wiley.
Pedhauzer, E. J. (1982). Multiple regression in behavioral research: Explanation and prediction ( $2 \mathrm{nd}$ ed.). Fort Worth, TX: Holt, Rinehart, and Winston.

Snyder, M., \& Ickes, W. (1985). Personality and social behavior. In G. Lindzey \& E. Aronson (Eds.), Handbook of social psychology (3rd ed., pp. 883-948). New York: Random House.

Staub, E. (1978). Positive social behavior and morality: Social and personal influences. San Diego, CA: Academic.

Tabachnick, B. G., \& Fidell, L. S. (1989). Using multivariate statistics. New York: HarperCollins.

Underwood, B., \& Moore, B. (1982). Perspective taking and altruism. Psychological Bulletin, 91, 143-173.

Zuckerman, M., Bernieri, F., Koestner, R., \& Rosenthal, R. (1989). To predict some of the people some of the time: In search of moderators. Journal of Personality and Social Psychology, 57, 279-293. 